\title{
Prevalence and Impact of Cerebrovascular Risk Factors in Patients with Giant Cell Arteritis: An Observational Study from the Spanish National Registry.
}

\section{Enrique Sánchez-Chica}

Puerta del Hierro University Hospital of Majadahonda: Hospital Universitario Puerta del Hierro Majadahonda

\section{María Martínez-Urbistondo}

Puerta del Hierro University Hospital of Majadahonda: Hospital Universitario Puerta del Hierro Majadahonda

\section{Ángela Gutiérrez-Rojas}

Puerta del Hierro University Hospital of Majadahonda: Hospital Universitario Puerta del Hierro Majadahonda

\section{Raquel Castejón}

Puerta del Hierro University Hospital of Majadahonda: Hospital Universitario Puerta del Hierro Majadahonda

\section{Juan A Vargas-Nuñez}

Puerta del Hierro University Hospital of Majadahonda: Hospital Universitario Puerta del Hierro Majadahonda

\section{Victor Moreno-Torres ( $\nabla$ victor.moreno.torres.1988@gmail.com )}

Puerta del Hierro University Hospital of Majadahonda: Hospital Universitario Puerta del Hierro Majadahonda https://orcid.org/0000-0002-9798-4514

\section{Research article}

Keywords: Giant cell arteritis, cerebrovascular events, cardiovascular risk factors.

Posted Date: February 10th, 2022

DOI: https://doi.org/10.21203/rs.3.rs-1260295/v1

License: (c) (i) This work is licensed under a Creative Commons Attribution 4.0 International License. Read Full License 


\section{Abstract}

OBJECTIVES. To assess the prevalence and impact of cerebrovascular risk factors (CRF) on major cerebrovascular events in patients with giant cell arteritis (GCA).

\section{METHODS.}

Analysis of the patients diagnosed with GCA identified in the Spanish Hospital Discharge Database between 2016 and 2018. Admissions due to cerebrovascular events (CVE, composed by stroke and transient ischemic attack) were compared to the admissions due to other causes. The factors related to cerebrovascular events were assessed by a multivariate logistic regression analysis.

\section{RESULTS.}

8,474 hospital admissions from patients diagnosed with GCA were identified. Mean age was 80.8 years and $36.4 \%$ were male. $67.2 \%$ were hypertense, $27.8 \%$ diabetic, $36.7 \%$ dyslipidemic, $14.2 \%$ smokers and $6.8 \%$ presented prior atherosclerosis diagnosis. Overall mortality rate was $6.5 \% .3 .4 \%$ of the admissions were motivated by CVE (stroke in $2.8 \%$ and TIA in $0.6 \%$ ). When compared with the admissions due to other causes, the patients who suffered from CVE presented a higher rate of male sex (36.2 vs $43.5 \%$, $p=0.007)$, hypertension ( $66.9 \%$ vs $74.4 \%, p=0.004)$, diabetes $(27.6 \%$ vs $33.7 \%, p=0.016)$ and atherosclerosis (6.6\% vs 10.2\%, $\mathrm{p}=0.0 .017)$. After adjustment, male sex ( $\mathrm{OR}=1.35,95 \% \mathrm{Cl} 1.06-1.72)$ and mainly hypertension $(\mathrm{OR}=1.44,95 \% \mathrm{Cl} 1.11-1.90)$ were associated with a higher risk of CVE.

\section{CONCLUSION.}

Hypertension, along with male sex, was the strongest risk factor for cerebrovascular events in GCA patients. In these high-risk patients, antiplatelet therapy should be re-considered and evaluated in prospective studies.

\section{Key Points}

1. Over 8,474 admissions in patients with GCA, $3.4 \%$ of them were motivated by serious cerebrovascular events.

2. Cardiovascular risk factors, along with atherosclerotic disease, were more frequent in patients with cerebrovascular events.

3. Male sex and hypertension were the only factor independently associated with a higher risk of cerebrovascular event.

4. In these high-risk patients, antiplatelet therapy should be re-considered and evaluated in prospective studies.

\section{Introduction}


Giant cell arteritis (GCA) is a chronic granulomatous vasculitis affecting the aorta and its main ramifications, with special predilection for the extracranial branches of the carotid artery [1]. GCA is a rare disease that presents almost exclusively in patients over 50 years-old. The highest prevalence has been described in Northern Europe countries, where females are also more frequently affected with a ratio that reaches 3 to 1 [2].

Clinically, the disease usually presents an insidious course with general manifestations including fever, asthenia or weight-loss, along with local symptoms due to arterial inflammation and vascular deficit such as headache, jaw claudication or transient vision loss [3]. These vascular events may indeed occur in up to $20-50 \%$ of patients with GCA and are responsible of the sometimes-abrupt onset of the disease. Apart from the extra-cranial branches of the carotid artery that determine the classic symptoms of the disease, cerebral ischemic events can also be seen, being the vertebrobasilar territory the most commonly affected $[4,5]$. Finally, severe arterial compromise can even lead to established ischemic events in theses territories, one of the most severe complications of the disease, with a high morbidity and mortality impact $[6,7]$. Usually, these ischemic events in GCA tend to occur during the inflammatory period of the vasculitis [8]. Also, several studies have reported a higher risk of cerebrovascular events in the presence of classical cardiovascular risk factors [7,9-12]. In light of the previous, prophylactic antiplatelet therapy was initially encouraged in the original EULAR recommendations [13]. However, since other reports did not confirm a solid effect of aspirin in GCA, aspirin use was no longer routinely recommended in the latest recommendations [14].

Therefore, the aim of our study was to analyze the prevalence and impact of cerebrovascular risk factors (CRF) in patients with GCA, to identify those who are at higher risk and could potentially benefit from antiplatelet therapy.

\section{Materials And Methods}

\section{Patients}

We performed an observational and retrospective analysis with data from The Spanish Hospital Discharge Database (SNHDD), a registry that belongs to the Spanish Ministry of Health. SNHDD includes demographic and epidemiological data and up to 20 discharge diagnoses carried out during admission defined by the International Classification of Diseases (ICD-10) from 1 January 2016. We selected hospital admissions from 1 January 2016 to 31 December 2018 for patients with a diagnosis within the ICD-10 code M31.5 (giant cell arteritis with polymyalgia rheumatica) and M31.6 (other giant cell arteritis), at any position in the diagnostic list. The study complies with the Declaration of Helsinki and was approved by the local research ethics committee.

Assessment of cerebrovascular events and identification of cardiovascular risk factors

Once patients with CGA diagnosis were selected, those whose admission was attributable to cerebrovascular events (CVE) were identified. CVE were considered if the main diagnosis was acute 
ischemic stroke (code I63) or transient ischemic attack (TIA, code G45).

In order to analyze the CRF, patients were tagged to suffer from any of them if the proper ICD-10 code or any other disease whose definition implied the mentioned risk factors was identified in the coding list. To this purpose, patients were identified as hypertense if they presented primary hypertension (code I10), hypertensive cardiac disease (111), hypertensive chronic kidney disease (112), hypertensive cardiac and chronic kidney disease (113) or secondary hypertension (115). Diabetes was identified by type 1 diabetes mellitus (E10), type 2 diabetes mellitus (E11) and other types of diabetes mellitus (E12). Dyslipidemia was defined by hypercholesterolemia (E78) and hyperlipidemia (E78.2 and E78.5). Tobacco was classified according to tobacco consumption (Z72.0) or nicotine dependence (F17). Atherosclerosis was considered by the homonymous code 170 .

$\underline{\text { Statistical analysis }}$

Categorical variables were reported as frequencies and percentages and continuous variables were presented as mean and standard deviation. The significance of baseline differences between admissions attributable to CVE and those who did not was determined by the chi-square, Fisher's or Student's $t$ test as appropriate. A multivariate logistic regression analysis was performed to determine the factors related to CVE in patients with GCA. For all the analyses, a significance level of 0.05 was set. Statistical analysis was performed using SPSS version 26.0 (IBM, Spain).

\section{Results}

\section{Patient's characteristics}

8,474 admissions in GCA diagnosed patients were identified between 2016 and 2018. The characteristics of the admissions and the population are shown in table 1. Overall, the mean age was 80.8 years-old and $36.4 \%$ were male. Regarding CRF, $67.2 \%$ were hypertense, $27.8 \%$ suffered from diabetes, $36.7 \%$ from dyslipidemia and in $14.2 \%$ the smoking habit was identified. $6.8 \%$ presented prior atherosclerosis diagnosis. Overall mortality rate was $6.5 \%$ and the mean average stay was 9.3 days.

\section{Cerebrovascular events}

Overall, $3.4 \%$ of the admissions were attributable to a cerebrovascular event (ischemic stroke in $2.8 \%$ and TIA in $0.6 \%$ ). When compared to the admissions due to other causes (Table 2), the patients who suffered from CVE presented a higher rate of male sex (36.2 vs $43.5 \%, p=0.007)$, a higher burden of cardiovascular risk factors as hypertension $(66.9 \%$ vs $74.4 \%, p=0.004)$ or diabetes $(27.6 \%$ vs $33.7 \%$, $p=0.016)$ and more atherosclerosis $(6.6 \%$ vs $10.2 \%, p=0.0 .02)$. No differences were found regarding age, ICU admission, mortality or average stays.

Finally, a multivariate analysis was performed to identify the factors related to cerebrovascular events (Table 3). After adjustment, male sex (OR= 1.35, 95\% $\mathrm{Cl} 1.06-1.72)$ and hypertension (OR=1.44, 95\% Cl 
1.11-1.90) were associated with a higher risk while diabetes ( $\mathrm{OR}=1.24,95 \% \mathrm{Cl} 0.96-1.60)$ and atherosclerosis (OR=1.44, 95\% $\mathrm{Cl} 0.96-2.14)$ did not.

\section{Discussion}

This nation-wide analysis is one of the largest studies exploring factors related to cerebrovascular events in GCA, confirming that male sex and hypertension determine a higher risk of stroke in patients with this disease.

In our registry, 3.4\% of GCA patients were admitted because of either stroke or TIA. While ischemic complications have been described in up to $50 \%$ of the patients, severe events such as TIA and stablished stroke have been identified in a similar proportion as in ours $[5,10,15]$. Despite the relative low prevalence, their impact is obviously significant.

In GCA, ischemic events occur in relation to intimal hyperplasia that eventually occludes the lumen of the vessel [16]. However, it has been pointed out that cardiovascular risk factors may increase the risk of ischemic events in these patients, since they are likely to be involved in the development of thrombotic phenomena on the damaged vessel, as occurs in atheromatous arterial disease $[10,12,17,18]$. In our study, patients with CVE presented a higher rate of male sex, hypertension, diabetes and more atherosclerosis, confirming that CRF contribute to the inflammatory injury of the vessel. However, in the multivariate analysis, only male sex and hypertension were related to CVE. Similar findings have been described by others, confirming that hypertension is the main factor related to cerebral ischemic events in the setting of GCA, over diabetes, dyslipidemia or tobacco $[5,7,10]$. Besides, hypertension is also the stronger risk factor of stroke in general population and male sex presents inherent higher risk of stroke [19].

In the light of the aforementioned, diagnosis and treatment of atherosclerotic disease might play a major role during GCA management. In addition to prompt identification and treatment of the cardiovascular risk factors, questions about prophylactic use of antiaggregant therapy arise. Prior retrospective cohorts have shown that aspirin-treated groups developed less cerebrovascular complications $[17,18]$, while more recent studies, including one metanalysis, have not confirmed that antiplatelet or anticoagulant therapy could reduce severe ischemic events in GCA $[8,20,21]$. After these, the latest EULAR recommendations did not encouraged again prophylactic antiplatelet treatment as in the original guideline. However, the not despicable prevalence of serious CVE and the prevalence and impact of the cerebrovascular risk factors in our cohort suggest that probably antiaggregant use in GCA should be more carefully analyzed. To this purpose, other studies should also consider the cardiovascular risk factors, atherosclerosis prevalence as well as the bleeding risk, in order to individualize the best approach.

Our study presents several limitations. Due to the database configuration, essential information such as antiplatelet, anticoagulant or steroid treatment prior to the admission and more complete data about the course of the disease was lacking. This information could have yielded a more complete understanding of the factors related to cerebrovascular events. In addition, cerebrovascular events were compared with 
admissions due to other causes and not to health-control patients. On one hand, this could have diminished the power of our findings. On the other hand, the weight of the risk factors was evaluated with other diseases and is not as accurate as when compared to controls. Altogether, we were aware of the limitations of the database through the study design and we only analyzed reliable and categorical data such as CVE. Despite these pitfalls, we believe that our results are valid and robust although prospective and multicentric studies are needed to confirm our findings.

In conclusion, our study reveals that hypertension, along with male sex, was the strongest risk factor of cerebrovascular events in GCA patients. In these high-risk patients, the debate about antiplatelet therapy should be re-considered and evaluated in prospective studies.

\section{Abbreviations}

Cl: Confidence interval.

CRF: Cardiovascular risk factors.

CVE: Cerebrovascular event.

GCA: Giant cell arteritis.

ICD: International Classification of Diseases.

ICU: Intensive care Unit.

SNHDD: Spanish Hospital Discharge Database.

TIA: transient ischemic attack.

\section{Declarations}

Conflicts of interest. The authors declare no conflicts of interest.

Funding. This work has been supported by a grant from Instituto de Salud Carlos III (Expedient number CM19/00223).

Availability of data and material (data transparency): I have had full access to all the data in the study and thereby accept full responsibility for the integrity of the data and the accuracy of the data analysis.

Code availability (software application or custom code): Stata v25 software (StataCorp. 2019. Stata Statistical Software: Release 16. College Station, TX: StataCorp LLC.)

Author contributions. All authors contributed to the study conception and design. Material preparation, data collection and analysis were performed by Enrique Sánchez-Chica, Víctor Moreno-Torres and María 
Martínez-Urbistondo. The first draft of the manuscript was written by Enrique Sánchez-Chica, Víctor Moreno-Torres, María Martínez-Urbistondo and Ángela Gutiérrez and all authors commented on previous versions of the manuscript. All authors read and approved the final manuscript.

Additional declarations for articles in life science journals that report the results of studies involving humans and/or animals

Ethics approval (include appropriate approvals or waivers): The study was approved by the Research Ethics Committee of the Hospital Universitario Puerta de Hierro in accordance with the Declaration of Helsinki.

Consent to participate (include appropriate statements): Patient consent was waived according to the Spanish law and ethics committee.

Consent for publication (include appropriate statements): Patient consent was waived according to the Spanish law and ethics committee.

\section{References}

[1] Crowson CS, Matteson EL, Myasoedova E, Michet CJ, Ernste FC, Warrington KJ, et al. The lifetime risk of adult-onset rheumatoid arthritis and other inflammatory autoimmune rheumatic diseases. Arthritis Rheum. 2011; 63:633-9. doi: 10.1002/art.30155.

[2] Gonzalez-Gay MA, Vazquez-Rodriguez TR, Lopez-Diaz MJ, Miranda-Filloy JA, Gonzalez-Juanatey C, Martin J, et al. Epidemiology of giant cell arteritis and polymyalgia rheumatica. Arthritis Rheum. 2009; 61: 1454-61. doi: 10.1002/art.24459.

[3] Levine SM, Hellmann DB. Giant cell arteritis. Curr Opin Rheumatol. 2002; 14:3-10. doi:

10.1097/00002281-200201000-00002.

[4]. Samson M, Jacquin A, Audia S, Daubail B, Devilliers H, Petrella T, et al. Stroke associated with giant cell arteritis: a population-based study. J Neurol Neurosurg Psychiatry. 2015; 86: 216-21. doi: 10.1136/jnnp-2014-307614.

[5] Gonzalez-Gay MA, Vazquez-Rodriguez TR, Gomez-Acebo I, Pego-Reigosa R, Lopez-Diaz MJ, VazquezTriñanes MC, et al. Strokes at time of disease diagnosis in a series of 287 patients with biopsy-proven giant cell arteritis. Medicine (Baltimore). 2009; 88: 227-35. doi: 10.1097/MD.0b013e3181af4518.

[6]. Pariente A, Guédon A, Alamowitch S, Thietart S, Carrat F, Delorme S, et al. Ischemic stroke in giant-cell arteritis: French retrospective study. J Autoimmun. 2019; 99:48-51. doi: 10.1016/j.jaut.2019.01.009.

[7] Uddhammar A, Eriksson AL, Nyström L, Stenling R, Rantapää-Dahlqvist S. Increased mortality due to cardiovascular disease in patients with giant cell arteritis in northern Sweden. J Rheumatol. 2002; 29: 
[8] Narváez J, Bernad B, Gómez-Vaquero C, García-Gómez C, Roig-Vilaseca D, Juanola X, et al. Impact of antiplatelet therapy in the development of severe ischemic complications and in the outcome of patients with giant cell arteritis. Clin Exp Rheumatol. 2008; 26: S57-62.

[9] Pego-Reigosa R, Garcia-Porrua C, Piñeiro A, Dierssen T, Llorca J, Gonzalez-Gay MA. Predictors of cerebrovascular accidents in giant cell arteritis in a defined population. Clin Exp Rheumatol. 2004;22: s13-7.

[10] Gonzalez-Gay MA, Piñeiro A, Gomez-Gigirey A, Garcia-Porrua C, Pego-Reigosa R, Dierssen-Sotos T, et al. Influence of traditional risk factors of atherosclerosis in the development of severe ischemic complications in giant cell arteritis. Medicine (Baltimore). 2004; 83: 342-7. doi:

10.1097/01.md.0000145369.25558.b5.

[11]. Salvarani C, Della Bella C, Cimino L, Macchioni P, Formisano D, Bajocchi G, Pipitone N, et al. Risk factors for severe cranial ischaemic events in an Italian population-based cohort of patients with giant cell arteritis. Rheumatology (Oxford). 2009; 48:250-3. doi: 10.1093/rheumatology/ken465.

[12] Nesher G, Berkun $Y$, Mates $M$, Baras $M$, Nesher R, Rubinow A, et al. Risk factors for cranial ischemic complications in giant cell arteritis. Medicine (Baltimore). 2004; 83(2):114-122. doi:

10.1097/01.md.0000119761.27564.c9.

[13] Hellmich B, Agueda A, Monti S, Buttgereit F, de Boysson H, Brouwer E, Cassie R, et al. 2018 Update of the EULAR recommendations for the management of large vessel vasculitis. Ann Rheum Dis. 2020; 79: 19-30. doi: 10.1136/annrheumdis-2019-215672.

[14]. Hellmich B, Agueda A, Monti S, Buttgereit F, de Boysson H, Brouwer E, et al. 2018 Update of the EULAR recommendations for the management of large vessel vasculitis. Ann Rheum Dis. 2020; 79: 1930. doi: 10.1136/annrheumdis-2019-215672.

[15]. Hočevar A, Ješe R, Tomšič M, Rotar Ž. Risk factors for severe cranial ischaemic complications in giant cell arteritis. Rheumatology (Oxford). 2020; 59: 2953-2959. doi: 10.1093/rheumatology/keaa058.

[16] Weyand CM, Goronzy JJ. Arterial wall injury in giant cell arteritis. Arthritis Rheum. 1999; 42(5):844-53. doi: 10.1002/1529-0131(199905)42:5<844::AID-ANR2>3.0.C0;2-M.

[17] Lee MS, Smith SD, Galor A, Hoffman GS. Antiplatelet and anticoagulant therapy in patients with giant cell arteritis. Arthritis Rheum. 2006; 54: 3306-9. doi: 10.1002/art.22141.

[18] Nesher G, Berkun Y, Mates M, Baras M, Rubinow A, Sonnenblick M. Low-dose aspirin and prevention of cranial ischemic complications in giant cell arteritis. Arthritis Rheum. 2004; 50(4):1332-7. doi: 10.1002/art.20171. 
[19] O'Donnell MJ, Chin SL, Rangarajan S, Xavier D, Liu L, Zhang H et al; INTERSTROKE investigators. Global and regional effects of potentially modifiable risk factors associated with acute stroke in 32 countries (INTERSTROKE): a case-control study. Lancet. 2016; 388: 761-75. doi: 10.1016/S01406736(16)30506-2.

[20] Berger CT, Wolbers M, Meyer P, et al. High incidence of severe ischaemic complications in patients with giant cell arteritis irrespective of platelet count and size, and platelet inhibition. Rheumatology 2009; 48: 258-61.

[21] Martínez-Taboada VM, López-Hoyos M, Narvaez J, et al. Effect of antiplatelet/anticoagulant therapy on severe ischemic complications in patients with giant cell arteritis: a cumulative metaanalysis. Autoimmun Rev 2014; 13: 788-94.

\section{Tables}

Table 1. Admitted patients in Spain with GCA

\begin{tabular}{ll} 
Admissions (N) & 8,474 \\
\hline Age (years) (Mean, SD) & $80.8(8.7)$ \\
\hline Male sex (N, \%) & $5386(36.4 \%)$ \\
\hline Hypertension (N,\%) & $5691(67.2 \%)$ \\
\hline Diabetes (N,\%) & $2358(27.8 \%)$ \\
\hline Dyslipidemia (N, \%) & $3111(36.7 \%)$ \\
\hline Smoking (N,\%) & $1205(14.2 \%)$ \\
\hline Atherosclerosis (N,\%) & $573(6.8 \%)$ \\
\hline ICU admission (N,\%) & $273(2.2 \%)$ \\
\hline Death (N,\%) & $549(6.5 \%)$ \\
\hline Stay (days) (Mean, SD) & $9.3(9.3)$
\end{tabular}

GCA: Giant cell arteritis, SD: Standard deviation, ICU: Intensive care Unit

Table 2. Differences among admissions related to a cerebrovascular event 


\begin{tabular}{llll} 
& $\begin{array}{l}\text { Cerebrovascular events } \\
(\mathrm{N}=285)\end{array}$ & $\begin{array}{l}\text { Other admission causes } \\
(\mathrm{N}=8,189)\end{array}$ & $\begin{array}{c}\text { p- } \\
\text { value }\end{array}$ \\
\hline Age (Mean, SD) & $80.3(8.7)$ & $80.8(8.7)$ & 0.356 \\
\hline Male (N,\%) & $124(43.5 \%)$ & $2964(36.2 \%)$ & 0.007 \\
\hline Hypertension (N,\%) & $212(74.4 \%)$ & $5479(66.9 \%)$ & 0.004 \\
\hline Diabetes (N,\%) & $96(33.7 \%)$ & $2262(27.6 \%)$ & 0.016 \\
\hline Dyslipidemia (N, \%) & $115(40.4 \%)$ & $2996(36.6 \%)$ & 0.109 \\
\hline Aterosclerosis (N,\%) & $29(10.2 \%)$ & $544(6.6 \%)$ & 0.017 \\
\hline Smoking (N,\%) & $38(13.3 \%)$ & $1167(14.3 \%)$ & 0.370 \\
\hline ICU admission (N,\%) & $10(3.5 \%)$ & $263(3.2 \%)$ & 0.437 \\
\hline Mortality (N,\%) & $22(7.7 \%)$ & $527(6.4 \%)$ & 0.224 \\
\hline $\begin{array}{l}\text { Average stay (days) (Mean, } \\
\text { SD) }\end{array}$ & $10(10.6)$ & $9.3(9.3)$ & 0.196
\end{tabular}

SD: Standard deviation, ICU: Intensive care Unit.

Table 3. Factors related to cerebrovascular event in patients with giant cell arteritis

\begin{tabular}{lll} 
& OR & $95 \% \mathrm{Cl}$ \\
\hline Age & 0.99 & $0.98-1.01$ \\
\hline Male sex & $\mathbf{1 . 3 5}$ & $\mathbf{1 . 0 6 - 1 . 7 2}$ \\
\hline Hypertension & $\mathbf{1 . 4 4}$ & $\mathbf{1 . 1 1 - 1 . 9 0}$ \\
\hline Diabetes & 1.24 & $0.96-1.60$ \\
\hline Atherosclerosis & 1.44 & $0.96-2.14$
\end{tabular}

OR: Odds ratio, Cl: Confidence interval. 